\title{
Escritura colaborativa en línea. Un estudio de la revisión textual compartida en la formación inicial de maestros
}

\author{
Online collaborative writing. A study of shared textual review in initial teacher edu- \\ cation
}

\author{
Elia Saneleuterio (iD) \\ e-mail: elia.saneleuterio@uv.es \\ Universitat de València. España
}

\author{
M. Begoña Gómez-Devís iD \\ e-mail: mabegode@uv.es \\ Universitat de València. España
}

\section{Resumen}

Presentamos, en el marco de los proyectos de innovación de la Universidad de Valencia, el análisis de una experiencia de escritura colaborativa en línea. Desde una perspectiva que reúne las tesis de escritura y evaluación como herramientas para aprender, se aplica una metodología de investigación-acción para el seguimiento de un proceso de aprendizaje colaborativo: escritura individual, con revisión y evaluación compartidas, a través de un diario virtual que recoge las sesiones presenciales de la asignatura Lengua Española para Maestros, de primer curso de las titulaciones de Magisterio. La muestra analizada, perteneciente a dos cursos académicos, corresponde a la actividad de 84 estudiantes, cada uno de los cuales moderó una conversación virtual con una media de 12-16 mensajes de autoría múltiple cada una, que fueron analizados mediante una técnica ad hoc de análisis de contenido. Como conclusiones más destacadas, los resultados han permitido identificar diferencias en el rendimiento asociadas a procesos de coautoría real favoreciendo la aparición de procesos argumentativos y reflexivos, y guía el trabajo de grupo hacia procesos cercanos a los esperados en las comunidades de aprendizaje. Asimismo, este trabajo invita a la reflexión sobre dos aspectos: el seguimiento de los participantes y la entrega de ayudas durante el proceso.

Palabras clave: escritura colaborativa en línea; revisión entre iguales; formación docente; alfabetización académica.

\section{Abstract}

The analysis of an online collaborative writing experience is presented, in the framework of the innovation projects of the University of Valencia. From a perspective that brings together the thesis of writing and assessment as tools to learn, an action research methodology is applied to monitor a collaborative learning process: individual writing, with shared review and evaluation, through a virtual diary that collects the face-toface sessions of the Spanish Language for Teachers subject, in the first year of the Teaching degrees. The sample analysed, belonging to two academic courses, corresponds to the activity of 84 students, each of whom moderated a virtual conversation with an average of 12-16 messages each by multiple authorship, which were analysed using an ad hoc technique of content analysis. The most prominent conclusions point at the results allowing for the identification of differences in performance, associated with real co-authorship processes, favouring the appearance of argumentative and reflexive processes, and guiding the group work towards processes closer to those expected in learning communities. Likewise, this work invites reflection on two aspects: the follow-up of the participants and the delivery of aid during the process.

Keywords: online collaborative writing; peer review; teacher education; academic literacy.

Recibido / Received: 15-01-2020

Aceptado / Accepted: 07-05-2020

Publicado / Published: 01-07-2020

Cómo referenciar este artículo / How to reference this article:

Saneleuterio, E., \& Gómez-Devís, M. B. (2020). Escritura colaborativa en línea. Un estudio de la revisión textual compartida en la formación inicial de maestros. Tendencias Pedagógicas, 36, pp. 59-73. doi: 10.15366/tp2020.36.05 


\section{Introducción}

Las investigaciones sobre escritura vienen poniendo de manifiesto su naturaleza procesual y destacan, sobre todo, el papel que tiene respecto del pensamiento. Entre otras, encontramos posiciones teóricas que van desde el uso epistémico de la escritura — critical writing - a la defensa de la escritura para el aprendizaje — writing to learn —. En efecto, podemos apreciar que el hecho de escribir puede cumplir una función comunicativa, transaccional o interpersonal — comunicarse o interactuar con otras personas- y al mismo tiempo puede funcionar para representar o representarse el mundo o las ideas - expresar conocimientos, teorías, sentimientos...-, es decir, para tomar conciencia, autorregularse intelectualmente o construir y hacer avanzar el pensamiento.

Desde esta perspectiva, y en el marco de los proyectos de innovación de la Universidad de Valencia ${ }^{1}$, presentamos el análisis de una experiencia de escritura colaborativa en línea desarrollada en las titulaciones de Grado de Maestro/a en Educación Primaria y Grado de Maestro/a en Educación Infantil. En ella se reúnen las tesis de escritura y evaluación como herramientas para aprender y para ello se diseñó una metodología docente activa acorde con el seguimiento de un proceso de aprendizaje colaborativo: planificación en pareja, escritura individual, con revisión y evaluación compartidas, a lo largo de un diario virtual que recoge los apuntes o informes correspondientes a las clases presenciales de la asignatura Lengua Española para Maestros, de primer curso de los grados de Maestro/a en Educación Infantil y Maestro/a en Educación Primaria.

Dicha práctica se originó como una estrategia para favorecer la inclusión de estudiantes de nuevo ingreso en el escenario de aprendizaje que se encuentran al llegar a la universidad, así como mejorar su competencia en la composición de textos cuyo sentido y significado implica elaborar, construir y reflexionar sobre los contenidos y procesos desarrollados en la sesión. Además de dar cuenta de lo aprendido, enfatizamos el aporte a la formación de futuros docentes que, en esta tarea, comienzan a ensayar la revisión de textos, algo que formará parte de su futura labor profesional. La fase de planificación podía realizarse en pareja, mientras que el proceso de escritura y reescritura quedó como responsabilidad individual. Entre el borrador y el informe definitivo tuvo lugar una fase de revisión virtual y colaborativa mediante el foro de la plataforma electrónica.

\section{Marco teórico}

En la actualidad, indagar el entramado procesual de la escritura o repensar las condiciones pedagógicas en las que pedimos escribir a los alumnos en las distintas etapas educativas son retos y hechos de numerosas y valiosas investigaciones. Concretamente en el ámbito universitario, por ejemplo, los trabajos sobre la composición escrita han establecido cuatro escollos sobre los que hay que actuar. En palabras de Carlino (2004), los estudiantes muestran de manera reiterada cuatro tendencias:

- la dificultad para escribir teniendo en cuenta la perspectiva del lector;

- el desaprovechamiento del potencial epistémico de la escritura;

- la propensión a revisar los textos solo en forma lineal y centrándose en aspectos locales y poco sustantivos;

- la dilación o postergación del momento de empezar a escribir.

Al observarlas, por separado o en conjunto, resulta evidente que sigue siendo tremendamente necesaria la evaluación específica y, así, la valoración de la lengua escrita en la educación superior. Como indica Sanz Moreno (2009), esta no solo sirve como factor de motivación tanto para alumnos como para profesores al permitirles tomar conciencia de la importancia de lo evaluado, sino que, desde el punto de vista docente, es imprescindible para hacerse una idea de las fortalezas y debilidades de nuestros estudiantes en cada uno de los aspectos de la composición de textos y, en consecuencia, poder ajustar la programación a sus necesidades e incluso llevar un seguimiento personalizado.

Además, una vez superada la figura del docente como actor principal y único en la transmisión y evaluación del aprendizaje, las instituciones educativas se plantean, cada vez más, la potencia de aprender con los otros y de los otros, de buscar la forma en que los alumnos cuenten con posibili-

${ }^{1}$ Los resultados de esta investigación provienen del proyecto «COL $\cdot L A B O R A$ : Grup d'Escriptura Acadèmica i Avaluació en Col-laboració», financiado por la Universidad de Valencia en las convocatorias de Programas de Innovación Docente 2018-2019 (Ref. UV-SFPIE_GER18-847067) y 2019-20 (Ref. UV-SFPIE_PID19-1106445). 
dades reales y significativas de aprender en grupo mediante la colaboración entre ellos para resolver problemas auténticos que supongan un uso situado del conocimiento. Así se activan las prácticas didácticas que permiten aprender a colaborar, es decir, atender las opiniones de otros discentes, valorarlas, buscar acuerdos y gestionar en equipo las soluciones generadas.

Erkens, Jaspers, Prangsma y Kanselaar (2005) sugieren que la principal ventaja de la escritura colaborativa, comparada con la individual, es la posibilidad de recibir y ofrecer retroalimentación inmediata y argumentativa, cuanto más si se produce online; en efecto, el carácter sincrónico y argumentativo de la tarea favorece el aprendizaje, ya que los estudiantes se consideran mutuamente fuentes de conocimiento, aparte de que negocian entre ellos los propósitos, planes, conceptos y dudas. De hecho, la alta valoración del aprendizaje colaborativo mediado por ordenadores se ha visto nutrida por líneas de investigación que, desde comienzos del siglo, se vienen interesando en analizar y comprender cómo la colaboración y la tecnología pueden favorecer la construcción del conocimiento y cómo el aprendizaje colaborativo mediado por ordenador puede mejorar la interacción y el trabajo en equipo (Schmidt, 2001; Scardamalia \& Bereiter, 2003; Bustos Sánchez, 2009).

Si bien es evidente que la tecnología ha tomado un papel relevante gracias a su flexibilidad para aplicar instrumentos variados y adaptados al contexto, así como a las necesidades del alumnado, es fundamental considerar la renovación de la metodología docente. No obstante, su introducción en las actividades de aprendizaje no representa un cambio innovador per se: se precisan cambios en el rol del profesor y los estudiantes, en la metodología y el sistema de evaluación; en otras palabras, experimentar e indagar el desarrollo de propuestas tecnopedagógicas para aprender escribiendo con los otros o para aprender solucionando problemas con los otros a través de revisión virtual entre pares o de la escritura en línea — On line Collaborative Writing-.

De entre las tecnologías para el soporte de los procesos de escritura en línea podemos destacar la wiki (Piscitelli, 2005) y los entornos para la construcción del conocimiento (Scardamalia \& Bereiter, 2006). Frente ambas opciones, nos decantamos por el empleo del foro virtual porque, aunque el proceso de escritura colaborativa se diluye, al ser el autor o autora quien debe incorporar o no los cambios propuestos, el procedimiento permite que se genere una discusión o diálogo explícito para justificar cada revisión, proceso que produce un aprendizaje metalingüístico que no queda garantizado mediante los otros dos procedimientos.

\section{Propósito y metodología}

El estudio se enmarca en los modelos metodológicos de la investigación-acción en el ámbito educativo (Bisquerra, 2014), y se contextualiza en un proyecto de innovación docente basado en experiencias previas (Gómez-Devís, 2014; Ramos, Chiva \& Gómez, 2017; Saneleuterio, 2015; Saneleuterio y García-Ramos, 2015). En concreto, los instrumentos empleados en dicho proyecto de innovación educativa son el foro virtual (borrador del informe, comentarios de revisión inter pares, informe definitivo y rúbricas de evaluación argumentadas), un cuestionario de autoevaluación y un cuestionario de satisfacción, ambos virtuales. Este artículo aborda el primero de ellos mediante la técnica de análisis de contenido (Bardin, 2002).

Los participantes son estudiantes de los grados de Maestro/a en Educación Infantil y Maestro/a en Educación Primaria, concretamente dos grupos de 42 alumnos cada uno, de la asignatura de primer curso Lengua Española para Maestros. Todos ellos, mayores de edad, fueron informados de la aprobación por parte del Vicerrectorado de que los grupos donde se habían matriculado formaban parte del proyecto de innovación mencionado, y otorgaron su consentimiento participando de manera voluntaria en la actividad, teniendo la opción de autoevaluar su desempeño, que se valoraría con un peso de hasta el $10 \%$ en la calificación final de la asignatura. No obstante, para proteger su identidad se utilizan seudónimos en los ejemplos donde se mencionan nombres propios.

Por nuestra experiencia docente en estas titulaciones hemos podido comprobar que, como demuestran estudios previos (Ruiz Flores, 2009), la tendencia mayoritaria en la universidad a la hora de revisar un texto, ajeno o propio, consiste en señalar únicamente las faltas de ortografía o los errores de contenido. En el contexto de una materia de formación lingüística, debería evidenciarse la insuficiencia o superficialidad de estas tendencias de corrección focalizadas en el uso del código, ya que invitan a pensar que estos aspectos constituyen lo más importante de su escrito.

De acuerdo con esta realidad, uno de nuestros objetivos pedagógicos perseguía dotar de estrategias que trascendieran la mera corrección ortográfica y gramatical en la revisión de textos, y así 
ahondar en cuestiones de estructura, sentido o adecuación al género. Esto se hizo con apoyo oral explícito durante las sesiones presenciales del grupo B, de manera que el profesor acompañaba a los alumnos en la fase de revisión y ejemplificaba cómo atender aspectos que trascendieran la tendencia a la revisión superficial. El feedback en estos casos no se produjo de manera escrita, ni con anotaciones en los borradores ni mediante intervenciones en el foro — que se dejaba íntegramente a disposición del alumnado-, sino que se dedicaron algunos minutos de las clases presenciales, especialmente durante las primeras semanas del cuatrimestre, a revisar en gran grupo —autores, revisores y docente- los borradores y comentarios publicados. Esta dinámica, que no se dio en el grupo A, ayudará a descubrir fortalezas o debilidades del proceso de regular el estilo expresivo del alumnado, para que tome conciencia de que la articulación entre intuición y reflexión es esencial en el uso escrito de la lengua.

Así pues, la presente aportación tiene el propósito de indagar qué contenidos o aspectos se revisaron efectivamente y con qué frecuencia, comprobando si hay diferencias significativas entre el grupo que funcionó autónomamente y el que contó con acompañamiento explícito o retroalimentación oral por parte de la profesora. En coherencia con este objetivo, nos centraremos en esta ocasión en estudiar los comentarios que en el foro virtual se publicaron en relación con cada borrador, aplicando la técnica de análisis de contenido a una muestra de varios cursos. Para ello, hemos elaborado un sistema categorial ad hoc.

Se consideraron los beneficios de la escritura colaborativa en el diseño del proyecto de innovación no solo porque esta ayuda a explicitar estrategias de redacción diferentes según la fase de composición, sino porque genera dinámicas que no se producen en la escritura individual (Álvarez Angulo, 2011). De entre ellas priorizamos las que se producen durante las fases de revisión, especialmente fructíferas en la mejora de la escritura académica en contextos universitarios (Saneleuterio \& García-Ramos, 2015; Martínez-Lorca \& Zabala-Baños, 2015), muy relacionadas con los procesos de evaluación de la escritura y muy oportunas, por tanto, en la formación de maestros y maestras (Gómez-Devís, García \& Saneleuterio, 2017; Gómez-Devís \& Saneleuterio, 2020).

\section{Diseño de la tarea de escritura}

El diseño de la tarea prevé un proceso de creación colectiva de un diario virtual de las sesiones de la asignatura. La publicación de los borradores requiere una revisión colectiva y compartida antes de su redacción definitiva. Así, además de que el resultado global es cooperativo — cada uno se encarga de una sesión, pero puede contar con las actas de todas las sesiones de la asignatura-, lo que verdaderamente es colaborativo es el proceso de revisión, de manera que cada informe individual incorpora, en realidad, las sugerencias que los compañeros han ido apuntando de manera argumentada.

El funcionamiento fluido de este foro se asegura mediante el consenso de algunas consignas, de modo que el conjunto de informes definitivos fuera lo más homogéneo posible y, además, que todos los estudiantes desempeñaran correctamente sus roles y ajustaran su nivel de participación a lo requerido. Son las siguientes:

- Cada sesión se aborda normalmente por dos secretarios o secretarias; ello obedece a que, en cada grupo, hubo veintiuna sesiones y cuarenta y dos estudiantes matriculados.

- El reparto de sesiones corre a cargo del grupo de estudiantes, así como su gestión, con el establecimiento de los criterios o procedimientos que el mismo determinará.

- El canal de comunicación exclusivo para todo el proceso relativo al diario de sesiones es la plataforma virtual de la universidad (Moodle).

- Cada alumno debe enviar, el mismo día de la sesión presencial, una primera versión del informe de manera individual. La planificación del texto puede elaborarse con la otra persona que también va a publicar los apuntes de la misma sesión.

- Las revisiones o propuestas de mejora se hacen a través de mensajes contextualizados que se publican en el mismo hilo del foro donde el autor o autora ha publicado su primer borrador.

- La versión definitiva es responsabilidad individual. Esta debe completarse y publicarse a los quince días de la primera publicación, incorporando las revisiones oportunas de los com- 
pañeros y contestando en el foro a aquellas que no se consideren adecuadas.

El proceso se completa con la participación del alumnado en su evaluación, tanto mediante evaluación inter pares (que complementa el trabajo de revisión colaborativa) como mediante el diseño de un instrumento virtual de autoevaluación, que se insertan en el enfoque de $e$-evaluación orientada al aprendizaje desde el que nace el proyecto y que ha merecido atención en otras ocasiones (GómezDevís \& Saneleuterio, 2017; Gómez-Devís et al., 2017).

Respecto a la decisión de utilizar el foro y no otros soportes de trabajo colaborativo, como pueda ser una wiki o un documento compartido, obedece a que cada revisión debe justificarse, no solo «corregirse», y el formato de chat permite que el autor o autora responda y matice o justifique lo que considere oportuno. Incluso es posible la contrargumentación entre revisores. En este sentido, entendemos que se trata de una estrategia pedagógica que promueve la figura del lector crítico, puesto que enseña a los estudiantes la manera específica de encarar los textos de su materia y dedica un tiempo en las clases al análisis de lo escrito. De un lado, es muy probable que el estudiante se interese verdaderamente en qué se dice, ya que va a ser evaluado sobre esta materia; y, de otro, desarrolla la capacidad de identificar los géneros textuales y los usos que se dan en la enseñanza de las disciplinas.

Finalmente, además de otorgar el protagonismo del proceso de aprendizaje a quien realmente aprende, se mitiga la tendencia tradicional del docente a monopolizar la actividad de enseñar y evaluar, limitando su responsabilidad a guiar el proceso de aprendizaje, mostrándose de manera accesible, así como a facilitar los instrumentos y criterios de evaluación.

\section{Análisis y discusión de los resultados}

Antes de aportar los resultados del análisis de las revisiones inter pares es necesario señalar que, en una fase de preanálisis o exploración previa, se detectaron como debilidades representativas de los textos publicados en el foro los siguientes aspectos: falta de planificación o planificación deficiente - reflejada en la repetición de aspectos en lugares diferentes del informe o en problemas de ordenación ilógica de la información-, errores en el uso de la información o en el desarrollo del contenido - evidenciados en comprensiones incompletas o incomprensión de ciertos aspectos explicados en clase-, dominio insuficiente de la norma que provoca errores de uso sistemáticos cuestiones principalmente ortográficas, léxicas y gramaticales de diverso tipo-, cierta dependencia de lo literal - transcripción de lo escuchado durante la clase sin reestructuración posterior-, escasa atención o falta de hábitos para la revisión — normalmente solo modifican lo que han señalado los compañeros, pero pocos aprovechan para una verdadera tarea de autorevisión-, etc. Dicho esto, sorprende que las revisiones efectuadas por los compañeros, especialmente de los primeros informes, no señalen estas deficiencias estructurales.

Tabla 1.

Comentarios alojados en el foro virtual de la asignatura (revisión colaborativa en línea)

\begin{tabular}{|c|c|}
\hline ID & 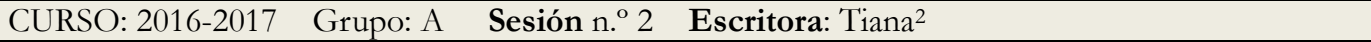 \\
\hline $\begin{array}{l}\text { A2 } \\
\text { R-1 }\end{array}$ & $\begin{array}{l}\text { Hola Tiana, creo que has explicado bien lo que hemos hecho en esta sesión. } \\
\text { En el cuarto párrafo, yo no pondría el «seguidamente». } \\
\text { En el quinto párrafo, en lugar de poner «uno expositivo», yo pondría «un texto expositivo», porque } \\
\text { anteriormente no has dicho nada de que el trabajo sea un texto, de manera que se entienda mejor. } \\
\text { Por lo demás yo lo he entendido todo, y me parece que está bien. } \\
\text { Un saludo, Águeda. }\end{array}$ \\
\hline $\begin{array}{l}\text { A2 } \\
\text { R-2 }\end{array}$ & $\begin{array}{l}\text { Buenas tardes, has resumido muy bien todo lo que hemos hecho hoy en clase. Sin embargo, si no } \\
\text { recuerdo mal, el primer borrador del texto expositivo en lugar de enviarlo, hay que entregárselo a la } \\
\text { profesora en } \quad \text { mano } \quad \text { el } \quad \text { día } \\
\text { Quitando ese pequeño error, el texto está muy completo, gracias. }\end{array}$ \\
\hline $\begin{array}{l}\mathrm{A} 2 \\
\mathrm{R}-3\end{array}$ & $\begin{array}{l}\text { Hola Tiana! } \\
\text { Creo que has resumido muy bien todos los contenidos que se han explicado hoy en clase. No } \\
\text { obstante, creo que cuando mencionas el libro de lectura que vamos a utilizar con la profesora, sería }\end{array}$ \\
\hline
\end{tabular}

2 Todos los nombres y apellidos de estudiantes se sustituyen por nombres de pila aleatorios, a modo de seudónimo, para preservar la identidad de los participantes. Los mensajes que copiamos a modo de ejemplo de los análisis realizados están transcritos literalmente, por lo que los defectos de expresión no han sido corregidos.

Tendencias Pedagógicas, 36, 2020, pp. 59-73. doi: 10.15366/tp2020.36.05 


\begin{tabular}{|c|c|}
\hline & $\begin{array}{l}\text { conveniente escribirlo con comillas. «Escribir textos expositivos en el aula. Fundamentación teórica y } \\
\text { secuencias didácticas para diferentes niveles.» } \\
\text { Muchas gracias por el diario de la sesión de hoy, un saludo! }\end{array}$ \\
\hline $\begin{array}{l}\text { A2 } \\
\text { R-4 }\end{array}$ & $\begin{array}{l}\text { Hola Tiana, estoy de acuerdo con mis compañeras en cuanto a la utilidad del resumen que has hecho. } \\
\text { No obstante, me gustaría puntualizar un pequeño error. Al inicio del resumen, en la parte derecha de } \\
\text { la esquina superior pones «Sesión } 2 » \text { y al final del resumen pones «Y esto ha sido todo de la sesión 3». } \\
\text { Salvo ese pequeño fallo, todo lo demás está perfecto. Muchas gracias. }\end{array}$ \\
\hline $\begin{array}{l}\text { A2 } \\
\text { R-5 }\end{array}$ & $\begin{array}{l}\text { Buenas tardes, Tiana. } \\
\text { Estoy de acuerdo con los pequeños fallos que ya te han corregido mis compañeros, y por lo demás, te } \\
\text { agradezco la realización del resumen y la participación en el diario de sesiones. } \\
\text { ¡Nos será de gran ayuda! } \\
\text { Un saludo. }\end{array}$ \\
\hline $\begin{array}{l}\text { A2 } \\
\text { R-6 }\end{array}$ & $\begin{array}{l}\text { ¡Hola Tiana! He lé́do el diario de la sesión de hoy que has realizado y estoy de acuerdo con mis } \\
\text { compañeros, la información nos será muy útil. No obstante, también me gustaría puntualizar un } \\
\text { pequeño detalle que desde mi punto de vista facilitaría la comprensión del texto. } \\
\text { En el párrafo 7, y en general cuando haces referencia al «Libro del alumno», yo lo pondría } \\
\text { entrecomillado, puesto que es el nombre del material, y así queda más claro. } \\
\text { Un saludo, y muchas gracias. }\end{array}$ \\
\hline $\begin{array}{l}\mathrm{A} 2 \\
\mathrm{R}-7\end{array}$ & $\begin{array}{l}\text { Hola Tiana. } \\
\text { Has hecho un gran resumen de la sesión } 2 \text { pero yo modificaría algunas cositas: } \\
\text { En primer lugar, en el segundo párrafo, cuando hablas del libro que vamos a trabajar en clase, } \\
\text { cambiaría la palabra «usaremos» por «utilizaremos» y después de «De este libro», añadiría una coma. } \\
\text { También, cuando hablas el trabajo contrastivo, eliminaría el «seguidamente». }\end{array}$ \\
\hline ID & CURSO: 2016-2017 $\quad$ Grupo: A $\quad{\text { Sesión n. }{ }^{\circ} 21}_{\text {Esc }}$ \\
\hline $\begin{array}{l}\text { A21 } \\
\text { R-1 }\end{array}$ & $\begin{array}{l}\text { ¡Buenos días, Irene! } \\
\text { Acabo de leer tu resumen de la sesión de ayer y he de felicitarte por el gran trabajo que has hecho. } \\
\text { Me gustaría comentarte un aspecto que quizás mejore la redacción: cuando usas conectores como «A } \\
\text { continuación», «Dicho esto» «Y por último» es mejor que pongas una coma. Además, cuando } \\
\text { escribes la palabra «video» deberías poner una tilde en la «i». Y por último, aunque supongo que será } \\
\text { un error sin haberte dado cuenta, acabas el resumen con un «ç». Espero que te haya podido ayudar } \\
\text { con estos apuntes. } \\
\text { ¡Un abrazo! }\end{array}$ \\
\hline $\begin{array}{l}\text { A21 } \\
\text { R-2 }\end{array}$ & $\begin{array}{l}\text { ¡Hola, Irene! } \\
\text { Coincido con Jose en los apuntes que ha señalado y añado que, en mi opinión, también debería } \\
\text { colocarse una coma entre las palabras «profesora» y «quién», en la segunda línea del primer párrafo. } \\
\text { No obstante, considero que has resumido muy bien lo que hicimos ayer en clase. También quiero } \\
\text { destacar la presentación ordenada y clara de tu escrito. } \\
\text { Muchas gracias por tu trabajo, Irene. Nos vemos mañana. }\end{array}$ \\
\hline $\begin{array}{l}\text { A21 } \\
\text { R-3 }\end{array}$ & $\begin{array}{l}\text { rdinario trabajo que has realizado. He detectado algunos errores pero } \\
\text { a te los han mencionado, por lo que ya no tengo nada más que añadir. }\end{array}$ \\
\hline $\begin{array}{l}\mathrm{A} 2 \\
\mathrm{R}-\end{array}$ & $\begin{array}{l}\text { ¡Buenos días, Irene! } \\
\text { Te felicito por tu redacción, pues considero que sigue una muy buena estructura y resume } \\
\text { perfectamente lo realizado en la sesión del martes } 9 \text { de mayo. No obstante, al leerlo, aparte de los } \\
\text { errores ya indicados por mis compañeros, te comento los siguientes: } \\
\text {-La palabra «quién» de la segunda línea no llevaría tilde, ya que su función es de relativo. } \\
\text { - En el primer párrafo, después de la palabra «menores», pondría un punto, ya que hablas de un } \\
\text { asunto distinto y se requiere una pausa mayor que la de la coma. } \\
\text { - Por último, al final del antepenúltimo párrafo, la palabra «que» se acentuaría, por tratarse de un } \\
\text { pronombre interrogativo indirecto. } \\
\text { Pese a estos detalles, una vez más, jenhorabuena por tu trabajo! } \\
\text { Clara }\end{array}$ \\
\hline ID & CURSO: 2015-2016 Grupo: B Sesión n. ${ }^{\circ} 1 \quad$ Escritora: Catalina \\
\hline
\end{tabular}




\begin{tabular}{|c|c|}
\hline & $\begin{array}{l}\text { Hola Buenas tardes, Soy Irene xx. } \\
\text { Catalina en mi opinión has hecho una buen acta, teniendo en cuenta que es la primera. Solo te voy a } \\
\text { decir una cosa que he podido observar. Cuando empiezas ha explicar [sic] el acta de sesiones, he } \\
\text { observado que los dos primeros párrafos empiezas con la misma palabra. En el primero "para } \\
\text { comenzar con dicha acta..." y en el segundo "Así pues, comenzamos..." Mi sugerencia es que, en el } \\
\text { segundo párrafo puedes empezar así "Así pues, seguidamente..." } \\
\text { Por todo lo demás, buen trabajo Catalina! }\end{array}$ \\
\hline $\begin{array}{l}\text { B1 } \\
\text { R-2 }\end{array}$ & $\begin{array}{l}\text { Buenas tardes, soy Lola xx. Para empezar, felicitar a Catalina por su Acta. Con ésta y la que } \\
\text { anteriormente yo misma subí, podemos observar dos maneras distintas e igualmente lícitas de realizar } \\
\text { esta tarea con gusto. } \\
\text { Con lo que respecta a los «fallos» o puntos a mejorar, en mi modesta opinión, si en mi acta uno de los } \\
\text { fallos fue que pequé de pocas comas, en el segundo párrafo de este documento encuentro que hay } \\
\text { demasiadas. En mi opinión, algún cambio por un punto y coma o empezar alguna nueva frase } \\
\text { quedaría mejor. Por otro lado, en el cuarto párrafo, al final del mismo, después del como que } \\
\text { empiezas a enumerar los tipos, yo no pondría la coma. } \\
\text { Por todo lo demás, muy buen trabajo y a seguir así compañeros/as. }\end{array}$ \\
\hline $\begin{array}{l}\text { B1 } \\
\text { R-3 }\end{array}$ & $\begin{array}{l}\text { Hola a todos mis compañeros, } \\
\text { Soy Noemí xx, alumna de la asignatura «Lengua Española para Maestros». Tras leer el acta de Catalina } \\
\text { xx, opino, al igual que otra compañera, que se hace un uso excesivo de las comas. Además añadir que } \\
\text { en el primer párrafo, se podría poner un sinónimo de retraso como «demora». En cuanto a los } \\
\text { tiempos verbales, algunas veces se expresa en pasado y otras en presente. } \\
\text { Espero haber ayudado. ¡Un saludo }\end{array}$ \\
\hline $\begin{array}{l}\text { B1 } \\
\text { R-4 }\end{array}$ & $\begin{array}{l}\text { Buenas tardes, soy Berta xx. } \\
\text { En el primer párrafo, creo que la última frase podría mejorarse ya que pienso que le sobran palabras y } \\
\text { podría escribirse de una manera más sencilla, en vez de «En consecuencia, éstos no están presentes } \\
\text { en el momento en el que el inicio de la clase da lugar» podría poner «En consecuencia, éstos no están } \\
\text { presentes en el inicio de la clase». } \\
\text { Por otra parte como ya bien ha dicho mi compañera Irene, cambiaría las primeras palabras de los dos } \\
\text { primeros párrafos, ya que se repiten. } \\
\text { Respecto al tercer párrafo, cambiaría la palabra «vuelcan» por «aparecen». } \\
\text { Por último, pienso que ha elaborada una muy buena acta, ya que ser de las primeras no es nada fácil, } \\
\text { así que sólo me queda felicitar a mi compañera por su buen trabajo. }\end{array}$ \\
\hline $\begin{array}{l}\text { B1 } \\
\text { R-5 }\end{array}$ & $\begin{array}{l}\text { Buenas tardes Soy Laura xx, y felicito a Catalina por su redacción, pero tenemos que comentar lo que } \\
\text { a nuestro juicio creemos que no está bien. } \\
\text { En el primer párrafo dice «no están presentes en el momento en el que el inicio de la clase da lugar», } \\
\text { repites «en el» en la misma frase creo que podrías cambiarlo por «no están presentes al inicio de la } \\
\text { clase», } \\
\text { En el tercer párrafo escribes «los alumnos/as», deberías escribir también el femenino en el artículo } \\
\text { «los». } \\
\text { No soy nadie para corregir, pero si para aprender. Enhorabuena Catalina y buen trabajo. }\end{array}$ \\
\hline $\begin{array}{l}\text { B1 } \\
\text { R-6 }\end{array}$ & $\begin{array}{l}\text { Buenos días, soy Pepa. } \\
\text { Voy a comentar algunos puntos que considero que no están del todo bien, desde mi punto de vista: } \\
\text { - Por lo que respecta al nombre de la población «Onteniente», puede mantenerse el nombre } \\
\text { Ontinyent, ya que está oficialmente reconocido. Sí es cierto que se debe colocar el «de» delante, pero } \\
\text { pudiendo mantenerse el nombre mencionado. Si queréis saber más sobre el origen del nombre os } \\
\text { animo a consultar este enlace: } \\
\text { Navarro, J. y Román, M. (2013). Historia de Ontinyent. Universidad de Alicante. Extraído el } 14 \text { de } \\
\text { febrero de } 2016 \text { de http://blogs.ua.es/historiaontinyent/2013/12/31/el-nom-dontinyent/ } \\
\text { BERNABEU GALBIS, ALFRED. Ajuntament d'Ontinyent, 1994. «El nom d’Ontinyent: títols } \\
\text { honorífics: la bandera i l'escut». Pág. 5-44. } \\
\text { - En cuanto al primer párrafo, lo resumiría de la siguiente manera, pues no me gusta la expresión } \\
\text { «sufren un retraso»: } \\
\text { En primer lugar y antes de empezar con la descripción de la sesión del día de hoy, cabe destacar que } \\
\text { algunos de los alumnos de la asignatura han accedido a la sesión más tarde de la hora prevista, pues } \\
\text { estaban solucionando algunos inconvenientes respecto a la asignatura Ciencias Naturales Para } \\
\text { Maestros y Lengua Española Para Maestros, las cuales se solapan. Del mismo modo, cuando han } \\
\text { entrado han podido seguir el ritmo de la clase habitual. } \\
\text { Repito, desde mi punto de vista, cambiaría lo indicado, pero el trabajo que ha hecho la compañera } \\
\text { Catalina es perfecto. } \\
\text { Un saludo. }\end{array}$ \\
\hline
\end{tabular}


Hola, ¡buenos días!

B1 Él acta de Catalina me parece muy bien redactada y estructurada, solo tengo que comentar la R-7 siguiente frase:

«A la vez, nos expone una serie de pautas las cuales nos ayudan a redactar correctamente un texto, así como conocer la realización de los distintos tipos de éstos como, argumentativo, explicativo, expositivo, etc.» cambiaría los «distintos tipos de éstos» por «los distintos tipos de textos como: argumentativos, explicativos, expositivos, etc.»

Por todo lo demás, muy buen trabajo!.

Hola compañer@s, comento lo que yo he visto.

B1 En el segundo párrafo, eliminaría la coma que sigue a «...previamente establecidos, desea.»

R-8 En el penúltimo párrafo donde pone «...a la clase.» Lo cambiaría por «en casa», porque si no me equivoco tenía que haberse leído en casa. En el mismo párrafo «A la vez, nos expone una serie de pautas las cuales nos ayudan a redactar correctamente un texto, así como conocer la realización de (lo cambiaría por reconocer) los distintos tipos de éstos como (lo cambiaría por texto, pudiendo ser: ...esto creo que ya ha sido comentado por otra compañera), argumentativo, explicativo expositivo, etc.»

Dar la enhorabuena a las dos compañeras por ilustrarnos con sus trabajos.

B1 Con respecto a la redacción del documento me gustaría felicitar a mi compañera ya que lo ha hecho

R-9 bastante bien, pero como ya han remarcado antes, en algunas partes he visto un excesivo uso de las comas.

Por otra lado no entiendo muy bien lo que quieres decir con "Al ser la primera sesión en la que dos de los alumnos/as de la clase deberán realizar el acta, vuelcan muchas dudas sobre el tema, por tanto, la profesora nos las aclara con la ayuda del dossier Indicaciones DIARIO DE SESIONES, así como el documento Proyecto de Innovación Docente, del que también hablamos, ambos encontrados en el aula virtual de la UV." . Me refiero a que la encuentro mal estructurada y la volvería a hacer de la siguiente manera:

«Al ser la primera vez que se debe hacer un acta sobre lo ocurrido en clase se dan muchas dudas sobre el tema. Debido a ésto la profesora se ayuda del dossier Indicaciones DIARIO DE SESIONES y del documento Proyecto de Innovación Docente, ambos subidos al aula virtual de la asignatura.» Un saludo.

Hola, soy Isidora xx, respecto al acta que ha hecho mi compañera Catalina tengo que decir que a mi

B1 parecer está muy bien. Me gustaría añadir que la palabra «dossier» sería más correcto sustituirla por la

R-10 palabra «dosier» con una sola s (con esto no quiero decir que la palabra dossier con dos s esté mal, solo que con una s está más aceptada). Dejo un link que he encontrado para estar segura de lo que he dicho es cierto.

http:/ / www.lavanguardia.com/cultura/20120614/54312467818/la-palabra-dosier-se-escribe-conuna-s-y-su-plural-es-dosieres.html

Por último, quiero felicitar a mis dos compañeras, porque lo han hecho las dos muy bien y sobre todo porque ser las primeras no es fácil.

ID CURSO: 2015-2016 Grupo: O Sesión n. $^{\circ} 16$ Escritora: Lola


¡Buenos días Lola! Comienzo dándote la enhorabuena por el acta que has realizado. Al ser una de las

B16R alumnas que tiene la asignatura de Ciencias Naturales para Maestros, me ha sido de gran ayuda ya

-1 que, me he podido informar de todo lo que hicisteis en la última sesión.

No pretendo ser quisquillosa, sin embargo, he observado algunos errores que considero que pueden mejorarse.

Para empezar, en el primer párrafo del punto 1 , se te ha olvidado colocar el acento al verbo «quedarán». Además, en la oración siguiente «... para la próxima sesión, ya que considera...», colocaría una coma donde te he señalado.

En el cuarto párrafo, en la oración «... la pregunta que teníamos pendiente; averiguar si era...», en lugar de haber puesto «;», yo colocaría 〈\$》, ya que no se trata de una enumeración, si no que estas explicando algo. De igual caso, en la oración «En cuanto a las otras dos; la aceptación correcta...»en lugar de «;», colocaría una \langle\rangle$\rangle$

En el sexto párrafo, repites dos veces seguidas «si deseas».

En el séptimo párrafo, has olvidado colocar un punto y seguido tras la palabra «Anagrama».

En cuanto al punto 2, en la primera línea del primer párrafo, ese «porqué» va separado ("por qué») ya que se trata de una pregunta indirecta.

En el segundo párrafo, seguidamente de la oración «La importancia de los párrafos se pone en

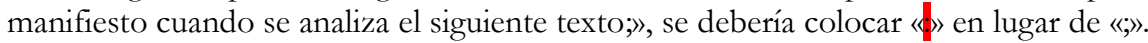

En cuando al punto 3, en la última línea del primer párrafo, olvidas colocar el signo de exclamación al principio de la oración. Además, considero que deberías señalar con comillas el microrelato con el fin de facilitar la lectura del lector.

En el punto 4, he observado que colocas «;» tras cada título. Creo que sería más conveniente colocar 〈ф) o, directamente, no colocar signos de puntuación, ya que en los títulos no es necesario.

Para finalizar, quería recordarte que el acta se debe realizar con la fuente «Times New Roman» y el tamaño 12, ya que he observado que en varios apartados utilizas distintos tipos de fuente y de tamaño.

Hasta aquí mis sugerencias. Espero que te sirvan de ayuda para la elaboración del acta definitiva. ¡Un saludo!

B16 Para empezar, felicitarte por tu acta. Al igual que mi compañera Catalina, yo soy otra de las alumnas

R-2 que tenía ciencias ese día, y me parece que tu acta está muy bien redactada.

A continuación, paso a comentarte algunos errores que he visto:

En el segundo párrafo del primer punto, en la frase: y como ha dejado a nadie encargado de realizar su acta... Le faltaría el no. (y como no ha dejado a nadie encargado de realizar su acta... ).

En la siguiente frase, pienso que le faltaría una coma. (Dicha permuta, se anota en el panel de clase para que quede constancia escrita).

En el punto dos, la frase: Aunque en los últimos tiempos la norma ha cambiado y antes se ponían más mayúsculas que ahora. Pienso que en lugar de la $\mathrm{y}$, deberías poner una coma. (Aunque en los últimos tiempos la norma ha cambiado, antes se ponían más mayúsculas que ahora).

Buenas tardes Lola, primero darte la enhorabuena por el acta realizada. A continuación, paso a

B16 nombrarte algunos detalles que modificaría: En el primer apartado suprimiría el punto que se R-3 encuentra antes del paréntesis:

«[...] marcar el nuevo párrafo y los diferentes asuntos. (Para ampliar información [...]» resultando así, «[...] marcar el nuevo párrafo y los diferentes asuntos (Para ampliar información [...]».

Por otra parte, añadiría un punto al finalizar la citación del libro de Cassany («[...] Cassany, D. (1995) La cocina de la escritura. Barcelona: Anagrama La estudiante cree que en el fragmento [...]») quedando de la siguiente manera: «[...] Cassany, D. (1995) La cocina de la escritura. Barcelona: Anagrama. La estudiante cree que en el fragmento [...]». Ten cuidado con los párrafos excesivamente breves, el cambio de fuentes e igual que con los usos del punto y coma, como por ejemplo en esta frase en la que en vez de punto y coma te recomendaría la utilización de los dos puntos:

«La importancia de los párrafos se pone de manifiesto cuando se analiza el siguiente texto;»

Además, como vimos en clase no es punto y final sino punto final: «[...] hay una errata y el punto y final debería ir detrás de las comillas». Por último, comentarte que la palabra «grosso modo» se escribe con dos «S», lo puedes comprobar en la RAE en el siguiente enlace: http://dle.rae.es/?id=JZm1qAN.

Un saludo. 


Hola, Lola.
B16 Para empezar felicitarte por tu acta y a continuación paso a nombrarte unos detalles a modificar.
R-4 En primer lugar, en el segundo párrafo del primer punto cuando dices: «y como ha dejado a nadie
encargado de realizar su acta, es Lola Álvarez quien la sustituirá», te falta el no ya que creo que
quieres decir que Sara no ha dejado a ningún encargado.
También he observado en el tercer párrafo en la frase: «Tras esto, se hace referencia la pregunta que
teníamos pendiente; », deberías substituir el punto y coma por dos puntos ya que pasas a enumerar.
Asimismo he encontrado un error muy recalcado en clase, las comillas deben ir antes que el punto y
tu aquí lo has hecho al revés («La amistad repugna la pobreza, como la flor a la oscuridad. Por eso, si
deseas si deseas conservar amigos, ocúltales tus penurias y sinsabores.»)
Para finalizar, cuando haces referencia a un siglo pones «siglo. XX;»y se escribe y sobra el punto ya
que no es una abreviación.


Hola Lola,

316R En primer lugar, decirte que el acta que has redactado resulta muy completa y de fácil lectura; creo

-5 que los contenidos impartidos en dicha sesión quedan explícitos para cualquier persona que no haya podido acudir a clase a ese día y clarificados para aquellas personas que sí que acudimos, pero que quizás nos quedamos con alguna duda.

A continuación paso a comentarte algunos errores que he detectado:

- En el punto 1: «La sesión empieza con la justificación al docente de la falta de asistencia de hoy».

Pienso que la oración quedaría más completa y clara de la siguiente forma: «La sesión empieza con la justificación al docente de la falta de asistencia por parte del alumnado en la presente sesión».

- En el tercer párrafo, recalcas correctamente la siguiente afirmación: «punto y coma el cual indica una gran relación con la oración que le precede».

Sin embargo, opino que la afirmación sería más adecuada si incluyeras el adjetivo semántico junto a relación, es decir especificas que la relación entre una oración y otra es semántica.

- Siguiendo con el tercer párrafo; después del cierre del paréntesis, en la oración que inicia con «Tras esto, se hace referencia a la pregunta que teníamos pendiente»; has obviado la preposición a que va ligada a la expresión «hacer referencia a».

- Seguidamente la oración continua de la siguiente forma: «averiguar si era punto y final, punto y aparte y punto y seguido. Se aclara que es punto final como única opción».

Mi sugerencia es cambiarla por: «averiguar si se denominaba punto y final, punto y aparte o punto y seguido. Se aclara que punto final es la denominación correcta».

- A continuación: «En cuanto a las otra dos; la aceptación correcta es punto y aparte y punto y seguido. Aunque se matiza que con el punto y seguido se permite decir punto seguido, pero no es lo más habitual».

Cuando nombras punto y aparte y punto y seguido; la presencia de la conjunción y es repetitiva pero necesaria, en este caso para diferenciarlas, creo que sería más correcto poner sin negrita la y central que funciona como copula entre una denominación y otra de los distintos signos de puntuación a los que te refieres.

Por otra parte, para terminar el párrafo sería más adecuado decir: «pero no suele ser lo más habitual», así utilizas un estilo más impersonal, ya que estas refiriéndote a los usos de los signos de puntuación.

- En el sexto párrafo: «Se mencionan también otros ejemplos: sólo, el cual en el libro aparece repetidamente acentuado y en la actualidad ya hay que ponerle la tilde».

Aquello que quieres explicar resulta confuso, ya que sin darte cuenta has obviado la conjunción adversativa no en: «y en la actualidad ya no hay que ponerle la tilde» o también podrías decir «y en la actualidad ya no es necesario ponerle tilde».

- En el punto 2, en el texto que reproduces de Anonymous, pones en las dos versiones «devotó», en lugar de «devotos».

- En este mismo punto, cuando terminas la exposición del texto correctamente puntuado y separado en párrafos; comentas que «en el 90 de los casos hay que colocar puntos y seguidos dentro de los párrafos» en lugar de «en el 90 por cien de los casos hay que colocar puntos y seguidos dentro de los párrafos».

- Por otra parte, en ese mismo apartado empiezas diciendo: «Tras la corrección, el pedagogo...». para referirte al profesor, durante el texto utilizas diferentes apelativos para referirte a él, como por ejemplo: catedrático, maestro, docente, profesor o pedagogo».

Me parece correcta esta técnica, ya que intentas no repetir el mismo apelativo cada vez y utilizar un léxico más rico, pero no todos estos sustantivos son sinónimos y creo que deberías cerciorarte antes de ponerlos si corresponden a la titulación o función correspondiente de la persona, más que nada porque se presta a confusiones.

- Continuando con el punto 2, en el párrafo: «Una vez los asistentes mencionan los acentos, el profesor avanza los conceptos de tilde, acento y tildes diacríticas, que expondrá el próximo lunes, así como el diptongo y el hiato».

Aquí, sería mejor poner: «avanza los conceptos de tilde, acento y tilde diacrítica», para que concuerden todos los conceptos en número, no hay razón para que tilde diacrítica vaya en plural, ya que cuando explicas el concepto, lo expones en singular.

- En el apartado 3, al final del primer párrafo: «Microficción, nanocuentos, microrelatos...hasta incluso hubo un autor que los denominó texticulos!».

Pones el signo de admiración únicamente al final de la frase, para cerrar. Es recomendable que lo pongas también al inicio. También creo que la expresión «hasta incluso» suena redundante, aunque sirve para enfatizar la afirmación, las dos palabras vendrían a ser sinónimos en esta expresión.

La oración puede enunciarse de la siguiente forma: «Microficción, nanocuentos, microrelatos...je incluso hubo un autor que lo denominó textículos!».

- En el segundo párrafo del punto 3, en la oración : «Al enseñársela a la profesora, con los ojos muy 
abierto...». Es necesario que cambies el número del adjetivo abierto y lo pongas en plural, ya que no concuerda con el sustantivo ojos.

- En el punto 4, inicias el párrafo con el adverbio luego; creo que sería más conveniente que utilizaras el adverbio posteriormente, por ser propio de un uso más formal como es el caso del contexto en el cual lo estás utilizando.

Fuente: elaboración propia.

La tabla 1 muestra el proceso de revisión vinculado a la publicación en la plataforma institucional de dos informes referidos a cada grupo participante, uno de principio de curso y otro de una de las últimas sesiones. La técnica de este análisis sobre el contenido de las revisiones sigue las recomendaciones de Bardin (2002) y Bustos Gisbert (2013). Con objeto de facilitar su lectura hemos utilizado varios colores para identificar las distintas categorías localizadas por los estudiantes: el color rojo señala aspectos relacionados con la ortografía en general — acentuación, puntuación, tipografía-; los marcados en verde atienden a la cohesión léxica —impropiedad, barbarismo léxico, monotonía, vaguedad-; el color azul muestra los problemas en la cohesión gramatical —-morfología, concordancia, régimen, sintaxis—; el morado indica relación con la adecuación — propósito, ética, registro, pertinencia, tipología textual, tratamiento bibliográfico, presentación y diseño-; y, por último, el amarillo apunta cuestiones de coherencia general —estructura, contenido, conexión y ambigüedad-. Estos ítems corresponden con las categorías utilizadas para el análisis (tabla 2).

Tabla 2.

Sistema categorial para el análisis de revisiones textuales (escritura académica).

\begin{tabular}{|c|c|c|}
\hline Supracategoría & Categoría & Unidades \\
\hline \multirow[t]{4}{*}{ Ortografía } & Ortografía general & $\begin{array}{l}\text { mayúsculas y minúsculas, separación de palabras, confusión, } \\
\text { omisión o adición de grafías, mal uso de las abreviaciones } \\
\text { gráficas... }\end{array}$ \\
\hline & Acentuación & $\begin{array}{l}\text { reglas generales de acentuación, diacríticos monosílabos o en } \\
\text { exclamativos e interrogativos, acentuación en diptongos, } \\
\text { triptongos e hiatos... }\end{array}$ \\
\hline & Puntuación & $\begin{array}{l}\text { coma entre sujeto y verbo o verbo y complemento, falta de coma } \\
\text { en incisos o marcadores, falta de signos de apertura o cierre, mal } \\
\text { uso del punto, del punto y coma... }\end{array}$ \\
\hline & Tipografía & mal uso de comillas, de cursiva, de negrita... \\
\hline \multirow[t]{4}{*}{ Cohesión léxica } & Impropiedad & poca precisión léxica o uso impropio de vocablos \\
\hline & Barbarismo léxico & $\begin{array}{l}\text { extranjerismo no marcado o incorrectamente adaptado, } \\
\text { neologismo innecesario... }\end{array}$ \\
\hline & Monotonía & $\begin{array}{l}\text { redundancia semántica, monotonía de léxico o poca variación, } \\
\text { monotonía de estilo, cacofonía }\end{array}$ \\
\hline & Vaguedad & falta de referencias léxicas \\
\hline \multirow[t]{5}{*}{$\begin{array}{l}\text { Cohesión } \\
\text { gramatical }\end{array}$} & Morfología & $\begin{array}{l}\text { flexión nominal o verbal incorrecta (tiempo, persona, género, } \\
\text { número...) }\end{array}$ \\
\hline & Concordancia & verbal o nominal \\
\hline & Régimen & preposicional o pronominal \\
\hline & Sintaxis & $\begin{array}{l}\text { anacoluto (falta o exceso de verbo o sintagma), estructura } \\
\text { sintáctica incorrecta... }\end{array}$ \\
\hline & Otros & usos verbales inadecuados (tiempos, voz pasiva...) \\
\hline \multirow[t]{5}{*}{ Adecuación } & Propósito & $\begin{array}{l}\text { no se percibe con claridad el propósito de recoger lo más } \\
\text { importante de la sesión o se percibe un propósito diferente }\end{array}$ \\
\hline & Ética & uso inadecuado de la cortesía, contenido no respetuoso \\
\hline & Registro & tecnicismo no justificado, coloquialismo \\
\hline & Pertinencia & $\begin{array}{l}\text { comentario no pertinente, irrelevante, demasiado obvio o no } \\
\text { interesante en absoluto para el destinatario del texto }\end{array}$ \\
\hline & Tipología textual & $\begin{array}{l}\text { falta de secuencias expositivas o argumentativas, no se incluyen } \\
\text { ejemplos o son inadecuados, no se incluyen incisos explicativos o } \\
\text { resultan inoperativos, no se incluyen imágenes o gráficos que } \\
\text { serían necesarios (o no se menciona dónde encontrarlos), no se } \\
\text { esquematizan ciertos contenidos o no se hace correctamente... }\end{array}$ \\
\hline
\end{tabular}




\begin{tabular}{|c|c|c|}
\hline & $\begin{array}{l}\text { Tratamiento } \\
\text { bibliográfico }\end{array}$ & $\begin{array}{l}\text { párrafos plagiados o no citados debidamente, incorrección en el } \\
\text { sistema de citación, referencias no homogéneas o con datos } \\
\text { omitidos... }\end{array}$ \\
\hline \multirow{2}{*}{$\begin{array}{l}\text { Coherencia } \\
\text { general }\end{array}$} & Contenido & $\begin{array}{l}\text { comentario no relacionado o no contextualizado, incorrección, } \\
\text { insuficiencia o falta de cuestiones relevantes comentadas en clase, } \\
\text { pobreza informativa }\end{array}$ \\
\hline & Ambigüedad & confusión en las ideas o varias interpretaciones posibles \\
\hline
\end{tabular}

Fuente: elaboración propia

Este sistema categorial, elaborado ad hoc para analizar el alcance de las revisiones colectivas, se inspira en los indicadores textuales de calidad (ITC) desarrollados por Didactext (Álvarez, 2010; Álvarez, 2013; Álvarez \& Andueza, 2017); aunque, una vez ajustados a nuestro contexto de investigación, ahonda en la clasificación de algunos ítems y reestructura otros, siendo el resultado aparentemente muy diferente.

Si seguimos con la discusión, en el grupo A, donde no hubo acompañamiento en el proceso de revisión por parte del docente, se aprecia una tendencia a la disminución del número de comentarios por informe a medida que avanza el cuatrimestre. Esto contrasta con los resultados obtenidos en el grupo B, cuyo interés residió en la incorporación de retroalimentación oral presencial específica por parte de la profesora respecto de la tarea revisora del alumnado. Como muestra la tabla 1 , es evidente la diferencia en la profundidad de los comentarios en cada periodo de la asignatura cuatrimestral.

En ambos ejemplos resulta evidente una mayor dosis de elaboración y reflexión en el proceso de revisión que la del grupo A. Mientras en el A las revisiones siguen centrándose fundamentalmente en cuestiones ortográficas puntuales, e incluso se pierde la incipiente variedad inicial, en el grupo B los aspectos que se comentan atienden todas las dimensiones del texto escrito. Es cierto que abundan las revisiones léxicas u ortográficas, pero también se apuntan sugerencias para la mejora de la adecuación o de comunicación del contenido.

Otra cuestión interesante que no podemos soslayar es la figura del revisor, cuya experiencia en la revisión textual no es la de un experto, o incluso sea la primera vez que deba acometer esta tarea. Además, el hecho de que el contenido de los textos que deben revisarse y reescribirse corresponda a los apuntes de la asignatura promueve la figura del lector crítico y tampoco consideramos que se trate de una labor para la que no se requieran algunas indicaciones o consideraciones previas.

En definitiva, aplicar a todo este proceso de escritura en colaboración la figura de un revisor cuya experiencia en evaluación no es la de un experto es complicado. Para mejorar el rendimiento individual y colectivo del proceso de escritura y reescritura - pues un mismo estudiante se desenvuelve en ambos parámetros-, se ha constatado la necesidad de facilitar a los estudiantes una serie de consideraciones sobre las que articular las revisiones colectivas.

\section{Conclusiones}

Los resultados evidencian los valores otorgados al grupo A, donde no hubo acompañamiento docente de ningún tipo: la directora del proyecto de innovación explicó la tarea en la primera sesión del curso, pero el profesor responsable de la asignatura no se implicó en el proceso, por lo cual no solo los informes y los comentarios mostraron poca profundidad, sino que también el nivel de actividad de los grupos fue llamativamente menor que en el B. Por el contrario, en el grupo cuyos estudiantes sí contaron con acompañamiento, aunque el número de revisores varía en cada uno de los textos publicados, se percibió mayor calado e intensidad en las aportaciones realizadas en el periodo 
final de la asignatura —-menor relevancia de los aspectos ortográficos o gramaticales-.

Así, se aprecia que las dificultades en el marco de la revisión textual son mayores al principio y en el grupo sin retroalimentación específica; por tanto, si nuestra intención es que los alumnos sean capaces de revisar más y mejor tendremos que dedicar tiempo específico de clase a instruir y guiar dicha revisión, dado que se demuestra una creciente implicación en los procesos de revisión colectiva en cuando existe retroalimentación oral específica. Además, la práctica de revisar para mejorar un texto que no es el propio es una clara apuesta en favor de la evaluación como estrategia formativa. Si uno de nuestros intereses era que los futuros maestros y maestras aprendieran con la evaluación, llámense escritores o revisores, nuestra investigación evidencia un hecho fundamental: que, gracias a la revisión colectiva de un texto fruto de la sesión presencial de la asignatura y una vez subsanados los errores derivados del dominio insuficiente del código, el desarrollo de destrezas en detección y diagnóstico de problemas con el contenido y la estructura de distintos textos propicia versiones personales notablemente mejoradas con respecto a producciones anteriores, además de aumentar las estrategias de cada estudiante como revisor/evaluador de un texto escrito.

Otra cuestión esencial de la investigación es la relacionada con la tesis de escribir es reescribir. En ambos grupos se consiguió que los estudiantes se habituaran a la fase de revisión textual de la producción propia y ajena, «conversación» entre alumnos junto a entrenamiento en formas de estructurar por escrito y presentar la información según disciplinas.

Finalmente, se recomienda la difusión entre el estudiantado de las categorías de análisis elaboradas por el equipo docente y presentadas en este trabajo (tabla 2), de manera que las puedan tener presentes en el proceso de revisión de cada borrador. Además de contribuir al desarrollo de una mente más lógica y mejor organizada, contribuyen a generar un vocabulario común, lo cual resulta clave a la hora de facilitar al alumnado la actividad de reflexión sobre la lengua y sus usos en determinados contextos.

\section{Referencias}

Álvarez Angulo, T. (2011). Revisar y reescribir textos académicos en la formación del profesorado. Revista Complutense de Educación, 22(2), pp. 269-294. doi: 10.5209/rev_RCED.2011.v22.n2.38493

Álvarez Angulo, T., \& Andueza Correa, A. (2017). Uso de tecnologías para facilitar el proceso de composición escrita: análisis del efecto de la plataforma RedacText 2.0 en la calidad de los textos académicos escritos por estudiantes de Magisterio. Revista Complutense de Educación, 28(1), pp. 283-305. doi: 10.5209/rev_RCED.2017.v28.n1.49449

Bardin, L. (2002). Análisis de contenido. Madrid: Akal.

Bisquerra, R. (coord.) (2014). Metodología de la investigación educativa (4. ${ }^{a}$ ed. Aumentada). Madrid: La Muralla.

Bustos Gisbert, J. M. (2013). Arquitextura. Salamanca: Ediciones Universidad de Salamanca.

Bustos Sánchez, A. (2009). Escritura colaborativa en línea. Un estudio preliminar orientado al análisis del proceso de co-autoría. RIED, 12(2), pp. 33-55. doi: 10.5944/ried.2.12.900

Carlino, P. (2004). El proceso de escritura académica: cuatro dificultades de la enseñanza universitaria. Educere, 26, pp. 321-327.

Erkens, G., Jaspers, E., Prangsma, M., \& Kanselaar, G. (2005). Coordination processes in computer supported collaborative writing. Computers in Human Bebavior, 18, pp. 173-190. doi: 10.1016/j.chb.2004.10.038

Gómez-Devís, M. B. (2014). Enseñar, evaluar, aprender e investigar en el aula universitaria de la mano de la materia Lengua para Maestros. @ttic. revista d'innovació educativa, 12, pp. 26-34. doi: 10.7203/attic. 12.3556

Gómez-Devís, M. B., García-Raffi, J. V., \& Saneleuterio, E. (2017). Educación lingüística y desarrollo de competencias en evaluación. Análisis de una experiencia en Magisterio. El Guiniguada. Revista de investigaciones y experiencias en Ciencias de la Educación, 26, pp. 132-145. doi: 10.20420/elguiniguada.2017.142

Gómez-Devís, M. B., \& Saneleuterio, E. (2017). Con la evaluación también se aprende. Percepciones y grado de satisfacción del alumnado en formación inicial en magisterio. En A. M. Aguilar López, \& B. Peña Acuña (Coords.) Didáctica de la lengua y la literatura: Buenas prácticas docentes, vol. II (pp. 167-192). Madrid: ACCI.

Gómez-Devís, M. B., \& Saneleuterio, E. (2020). Los procesos de revisión textual en entornos vir- 
tuales de aprendizaje. Evaluar para aprender en la universidad. Research in Education and Learning Innovation Archives, 24, pp. 1-17. doi: 10.7203/realia.24.16048

Martínez-Lorca, M., \& Zabala-Baños, C. (2015). Enseñando y aprendiendo a escribir en la universidad: Cuando los revisores son los compañeros. REDU-Revista de Docencia Universitaria, 13(3), pp. 105-124. doi: 10.4995/redu.2015.5422

Piscitelli, A. (2005). Internet. La imprenta del siglo XXI. Barcelona: Gedisa.

Ramos, G., Chiva, I., \& Gómez, M. B. (2017). Las competencias básicas en la nueva generación de estudiantes universitarios: Una experiencia de Innovación. REDU. Revista de Docencia Universitaria, 15(1), pp. 37-55. doi: 10.4995/redu.2017.5909

Ruiz Flores, M. (2009). Evaluación de la lengua escrita y dependencia de lo literal. Barcelona: Graó.

Saneleuterio, E. (2015). Revisión y recepción de la retroalimentación en Lengua Española para Maestros. Estudio comparativo. Huarte de San Juan. Filología y Didáctica de la Lengua, 15, pp. 23-42. Recuperado de https://academica-e.unavarra.es/handle/2454/20370.

Saneleuterio, E., \& García-Ramos, D. (2015). Producción y revisión de textos escritos. Diseño cooperativo para la optimización del aprendizaje lingüístico de futuros maestros. En R. Pérez Pérez, A. Rodríguez-Martín, \& E. Álvarez-Arregui (Eds.) Innovación en la Educación Superior: desafios y propuestas (pp. 425-432). Oviedo: Ediciones de la Universidad de Oviedo.

Sanz Moreno, Á. (2009). Orientaciones para la corrección de textos escritos. Gobierno de Navarra.

Scardamalia, M., \& Bereiter, C. (2003). Knowledge building. En J. W. Guthrie (Ed.) Encyclopedia of Education (pp. 1370-1373). New York, USA: Macmillan Reference. Recuperado de https://ikit.org/fulltext/2003_knowledge_building.pdf

Scardamalia, M., \& Bereiter, C. (2006). Knowledge building: Theory, pedagogy, and technology. En K. Sawyer (Ed.) Cambridge Handbook of the Learning Sciences (pp. 97-118). New York: Cambridge University Press. doi: 10.1017/CBO9780511816833.008

Schmidt, K. (2001). Computer-supported cooperative work and learning. Barcelona: UOC. FREREF ICT workshop. Recuperado de https://www.uoc.edu/web/esp/art/uoc/schmidt0202/schmidt0202.html 